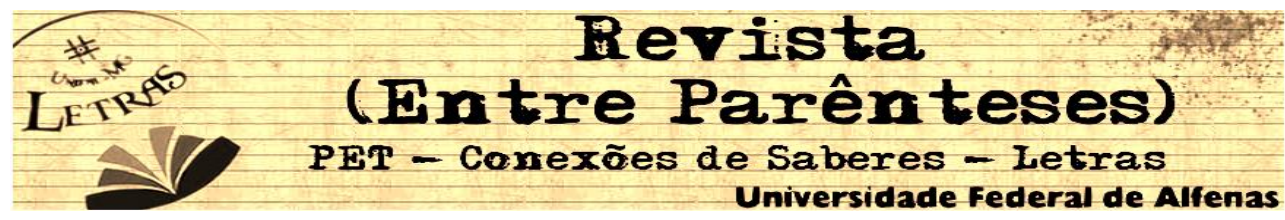

\title{
A TECNOLOGIA E OS MATERIAIS DIDÁTICOS NO ENSINO DE ESPANHOL PARA BRASILEIROS: PENSANDO A FORMAÇÃO DE ALUNOS PARA ALÉM DE ESTRUTURAS LINGUÍSTICO- NORMATIVAS
}

\author{
Kátia Aparecida da Silva Oliveira ${ }^{1}$ \\ UNIFAL-MG \\ (katiaoli@gmail.com) \\ Gabrielly Aparecida Araujo² \\ UNIFAL-MG \\ (gabrielly57@live.com)
}

\begin{abstract}
Resumo: A cada dia se apresentam novas propostas para o ensino do espanhol em diferentes contextos, especialmente para a educação básica, além de infindáveis questionamentos que envolvem desde os seus objetivos e até a formação dos futuros professores da língua. Nas OCEM encontramos a proposta de que o ensino do espanhol não esteja restrito ao desenvolvimento único de habilidades e competências linguísticas. Assim, considera-se que o ensino de uma língua estrangeira comporta uma série de elementos extralinguísticos, sociais, culturais e históricos, entre outros, importantes para a formação integral dos alunos. Acreditamos que, com a presente era tecnológica, faz-se necessário pensar em outros exemplos de materiais didáticos, além do livro didático, que de fato estejam contextualizados à realidade atual dos alunos. Os novos recursos digitais possibilitam novas formas de ensino/aprendizagem de línguas, pois oferecem formatos diferentes dos utilizados convencionalmente no ambiente escolar. Através dessa nova abordagem, acredita-se facilitar a real inserção do aluno no contexto linguístico e sociocultural da língua espanhola, uma vez que a facilidade de acesso às mídias contribui para a expansão dos instrumentos didático-pedagógicos adotados pelos docentes.
\end{abstract}

Palavras-chave: Espanhol; Ensino de línguas estrangeiras; Materiais didáticos; Tecnologia e ensino.

Resumen: Cada día más se nos presentan nuevas propuestas para la enseñanza de español en diferentes contextos, especialmente para la educación básica, además de una infinidad de cuestionamientos que tratan desde sus objetivos hacia la formación de futuros profesores de tal lengua. En las OCEM encontramos la propuesta de que la enseñanza de español no se limite al desarrollo único de habilidades y competencias lingüísticas. Así, pues, se considera que la enseñanza de una lengua extranjera está relacionada a una serie de elementos extralingüísticos, sociales, culturales e históricos, entre otros, importantes para la formación integral de los alumnos. Creemos que, con la actual era tecnológica, se hace necesario pensar en otros modelos de materiales didácticos, además del libro didáctico, que estén realmente contextualizados a la realidad de los estudiantes. Los nuevos recursos digitales posibilitan nuevas formas de enseñanza/aprendizaje de lenguas, una vez que ofrecen formatos diferentes de los utilizados convencionalmente en el ambiente escolar. A través de este nuevo abordaje, se cree que se facilita la real inserción del alumno en el contexto lingüístico y sociocultural de la lengua española, ya que la facilidad de acceso a las mídias contribuye para la expansión de los instrumentos didáctico-pedagógicos adoptados por los docentes.

Palabras-clave: Español; Enseñanza de lenguas extranjeras; Materiales didácticos; Tecnología y enseñanza.

\footnotetext{
${ }^{1}$ Professora de Literatura Espanhola do Curso de Letras da Universidade Federal de Alfenas UNIFAL-MG.

${ }^{2}$ Graduando em Letras da Universidade Federal de Alfenas (UNIFAL-MG)
} 


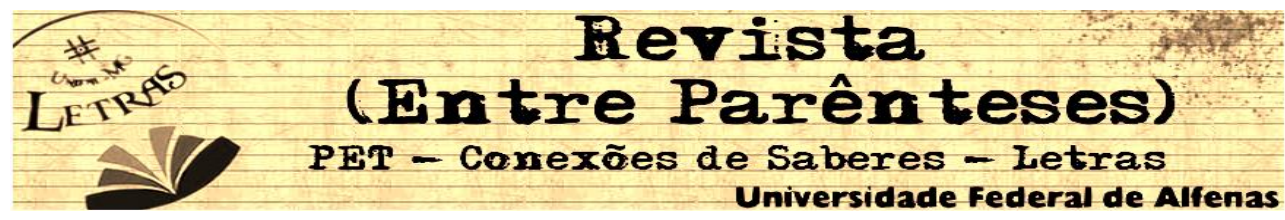

“(...) a minha questão não é acabar com a escola, é mudá-la completamente, é radicalmente fazer que nasça dela um novo ser tão atual quanto a tecnologia. Eu continuo lutando no sentido de pôr a escola à altura do seu tempo. E pôr a escola à altura do seu tempo não é soterrá-la, mas refazê-la." - Paulo Freire

As discussões acerca da implantação do ensino obrigatório de língua espanhola na rede de ensino regular brasileira não são recentes em nosso panorama político e educacional, porém, com a aprovação da lei 11.161 de agosto de 2005, que criou a obrigatoriedade do ensino dessa língua no ensino médio, pode-se perceber que se multiplicaram as vozes que se levantam propondo modelos para a implantação e ensino do ensino desse idioma no Brasil.

A cada dia se apresentam novas propostas para as formas como deve ser ensinado o espanhol, sem contar os infindáveis questionamentos que envolvem desde os seus objetivos e até a formação dos futuros professores de espanhol. Pensando no oferecimento do ensino do espanhol em nossas escolas, em 2006 foram publicadas pelo Ministério da Educação as Orientações Curriculares Nacionais para o Ensino Médio (doravante OCEM), com um capítulo dedicado aos conhecimentos de espanhol, documento que apresenta reflexões sobre os objetivos do ensino da língua espanhola no Brasil, levando em consideração a realidade e as necessidades dos alunos que cursem essa língua estrangeira, uma vez que embora o oferecimento do ensino de língua espanhola seja obrigatório para as escolas de ensino médio, é optativa para os seus alunos.

Como um documento oficial, as OCEM não deixam também de propor diretrizes para o ensino desse idioma, ainda que esclareçam que o ensino da língua espanhola deve ser sempre discutido pelos professores e comunidade escolar onde se dá esse ensino:

O objetivo destas orientações é o de sinalizar os rumos que esse ensino deve seguir, o que faz com que tenham um caráter minimamente regulador, do contrário, não haverá razão em fazer tantos esclarecimentos, marcar posições teórico-metodológicas, sugerir caminhos de trabalho etc. No entanto, para que esse caráter regulador ganhe sentido e produza efeitos, sabemos que serão necessários muitos outros passos, entre os quais destacamos o de 


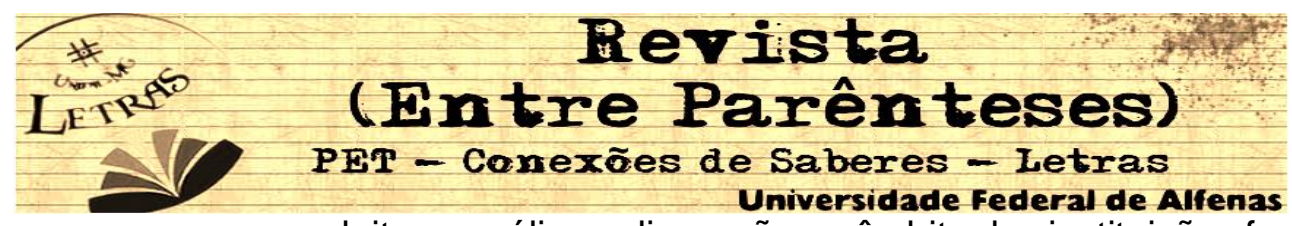

sua leitura, análise e discussão no âmbito das instituições formadoras de professores, em conjunto com os indivíduos em formação, e também o de sua leitura, análise e discussão por parte do coletivo das escolas. (OCEM, 2006, p. 127)

Trata-se de um documento que embora seja oficial e que, portanto, tem um papel prescritivo, cria uma abertura democrática para que o processo de ensino de espanhol seja construído não só pelas diretrizes que apresenta, mas também pelos seus protagonistas.

Nas OCEM encontramos a proposta de que o ensino do espanhol não esteja restrito ao desenvolvimento único de habilidades e competências linguísticas. Considera-se que o ensino de uma língua estrangeira comporta uma série de elementos extralinguísticos, sociais, culturais e históricos, entre outros, importantes para a formação integral dos alunos. Ao reconhecer a diversidade que compõe as culturas dos diferentes povos falantes da língua espanhola, cria-se a possibilidade de que o aluno brasileiro reflita, a partir da diferença entre as culturas estrangeiras e da sua própria cultura, sobre a sua identidade e sobre o seu papel como cidadão. Como diz Goettenauer (2005: 64):

A questão não é apenas sensibilizar o aluno e buscar formas para ensejar atitudes imparciais diante de outros valores, outras tradições, outros modos de ver, viver e nomear a realidade. Trata-se de algo bem mais complexo: acolher o outro e compartilhar com ele hábitos, costumes, idéias, posicionamentos etc. O domínio de outro idioma não se reduz à mera aquisição de um instrumental: algo que se maneja com maior ou menor facilidade para alcançar um propósito conseguir um emprego, viajar, escrever cartas, prestar o vestibular etc. apropriar-se de uma língua distinta da materna é apropriar-se de novas lentes para mirar o mundo.

O ensino de língua espanhola, nesse sentido, apresenta-se como mais um elemento que contribui para a formação da identidade de nossos alunos. Deixando de ser puramente instrumental, a língua espanhola não deve ser mais uma mera ferramenta da qual o aluno se utiliza para chegar a um determinado conhecimento, no caso, por exemplo, de leituras em língua espanhola, ou mesmo um facilitador para a comunicação em situações específicas. Com o foco no ensino da diversidade, da diferença, e consequentemente, na reflexão acerca da cultura estrangeira em relação 


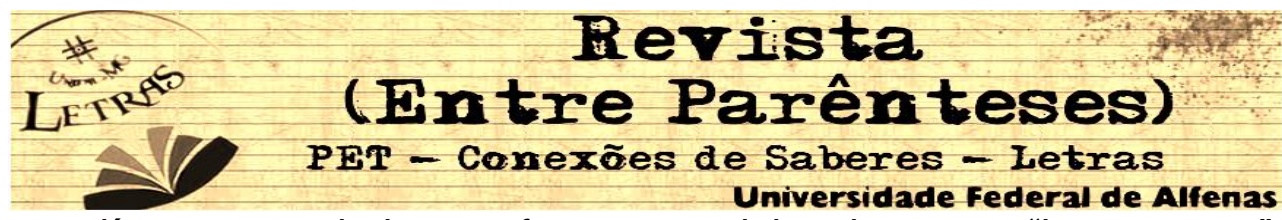

à materna, a língua espanhola transforma-se e deixa de ser um "instrumento" para ser também parte constituinte daquele que a aprende.

A partir da diferença, do contato com outra língua e naturalmente com 0 desenvolvimento de outro olhar sobre o mundo, é importante considerar que também é possível desenvolver o senso de cidadania nas aulas de língua estrangeira, já que "A reflexão sobre o papel da língua que se estuda e das comunidades que as falam, na sua complexa relação com o mundo em geral e com o nosso próprio espaço e a nossa própria língua, é de crucial importância na constituição dessa cidadania. " (OCNEM, 2006, p. 132).

Formar cidadãos é uma das mais importantes atribuições da escola, assim, pode-se considerar essencial que tenhamos no ensino de espanhol, e de qualquer outra língua, mais uma abertura para a constituição dos cidadãos que teremos no futuro, principalmente se pensarmos que o ensino de línguas estrangeiras possibilita a reflexão sobre diferentes contextos e práticas sociais.

Com proposta das OCEM de que o ensino de espanhol deverá contribuir para a formação integral dos alunos e com o importante papel que recebem os elementos culturais, históricos e sociais em meio ao processo de ensino-aprendizagem dessa língua, parece-nos pertinente pensar na forma como esses elementos se apresentam nos materiais didáticos que temos disponíveis atualmente.

Como material didático, podemos considerar todos os materiais utilizados pelo professor, segundo as suas necessidades, para o desenvolvimento de suas aulas. Nas palavras de Gargallo (1999: 49):

Todos aquellos recursos que - en soporte impreso, sonoro, visual o informático - empleamos en la enseñanza de una lengua extranjera aparecen aglutinados bajo el término materiales didácticos. Los materiales constituyen la exteriorización del método, su puesta en práctica en el aula con un fin preciso; (...) los materiales reflejan una manera de entender la naturaleza del lenguaje y la naturaleza del proceso de aprendizaje de una lengua extranjera. Los materiales concretan nuestra particular forma de entender la enseñanza.

Como diz Gargallo, o material didático é um dos elementos que refletem a postura que assume o professor frente a questões relacionadas ao ensinoaprendizagem de uma língua. A escolha de um determinado material deve ser, dessa 


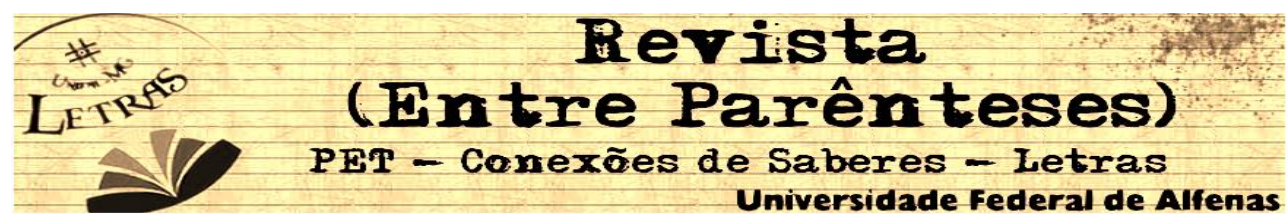

forma, intimamente ligada aos objetivos e práticas determinados pelo professor em um contexto de ensino.

O professor encontra-se assim com uma infinidade de possibilidades de adoção ou criação de materiais, embora nem sempre faça uso delas. Não há como negar que ainda hoje o livro didático é o tipo de material mais utilizado pelos professores para o ensino de idiomas em nosso país. Tratando dessa questão, temos as seguintes palavras de Bohn (1998, 293):

A grande maioria dos professores de língua, especialmente onde os recursos são limitados como em nosso país, usam um livro, um programa para as atividades rotineiras de sala de aula. A dependência do professor ao programa varia de acordo com o seu treinamento, objetivos de ensino, tempo disponível, validade dos materiais e recursos disponíveis em sua escola e comunidade. Podese, no entanto, afirmar que a experiência dos professores de línguas tem demonstrado que tanto o professor como o aluno e as atividades desenvolvidas na sala de aula são profundamente dependentes dos materiais utilizados para implementar o processo de aprendizagem e educativo.

A falta de recursos para aquisição de diferentes materiais didáticos, boas bibliotecas, cinema, teatro etc, limitam naturalmente as possibilidades que têm os professores de criar ou ter acesso a materiais distintos daquele a que, em geral, têm acesso: o livro didático. Claro está também que unida a essa questão da dificuldade de acesso a diferentes materiais, temos a questão do despreparo de boa parcela dos professores de idiomas. Seja pela inexperiência ou por uma formação deficiente, muitos professores assumem o livro didático como um guia para suas aulas. Nesses casos, o conhecimento da língua estrangeira e da diversidade cultural dos povos falantes dessa língua é resguardado pelo livro que pode apresentá-los ou não.

Com as dificuldades que enfrentamos, sejam elas a falta de recursos ou mesmo, em alguns casos, o despreparo dos docentes responsáveis pelo ensino de espanhol. Não se pode negar a importância do livro didático no ensino regular. Por mais que em algumas situações esses problemas já tenham sido vencidos, em geral ainda é prioritariamente (mas não exclusivamente, como veremos) com esse material que têm contato professores e alunos, além do fato de que ele contribui de forma significativa para a construção dos conhecimentos nas aulas de língua estrangeira. 


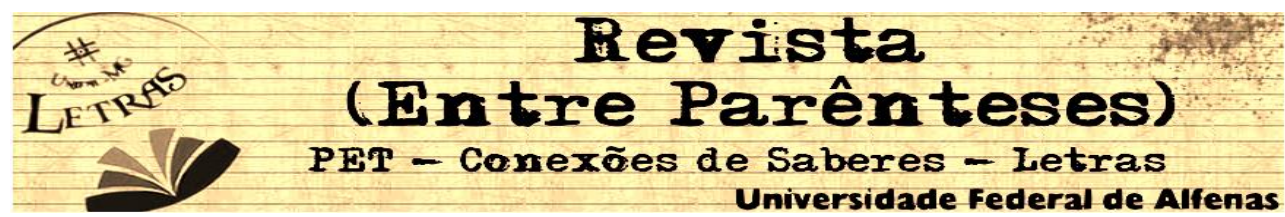

O material, no caso o livro didático, ocupa dessa maneira um papel importante no contexto de ensino, podendo ser o ponto de partida para discussões, para a reflexão e para o contato com outros recursos didáticos. Porém, o material ou recurso didático só tem serventia se for utilizado por "mãos hábeis". Explicando melhor, é incontestável o fato de que o material deve ser um instrumento nas mãos do professor de língua estrangeira, utilizado para a idealização e concretização de seus objetivos em aula. Como comenta Bohn (1998, 294):

Os materiais são vistos como uma fonte inspiradora de atos de linguagem, frutos da interação do professor com os seus alunos, dos alunos com os seus colegas; os materiais servindo de apoio para executar certas atividades que gerarão novas interações e novas tarefas de aprendizagem. O professor é visto como um gerenciador da ação didática, da ação comunicativa interpessoal e de todo o processo de aprendizagem.

Sendo "uma fonte inspiradora dos atos da linguagem", como diz Bohn, o livro didático ou outro material, antes de ser adotado, deve ser analisado a partir dos objetivos que o professor tiver para a situação de ensino para a qual pretende utilizálo, mesmo porque o fato de um material ser adequado para uma situação não significa que o seja para outra diferente.

Mas pensando especificamente no caso da língua espanhola, temos de considerar que os materiais didáticos para seu ensino foram por algum tempo pouco produzidos em nosso país. Dessa maneira, ainda que saibamos que o ensino de língua espanhola já houvesse sido oferecido nas escolas brasileiras há algumas décadas, a pouca procura pelo ensino dessa língua durante algum tempo fez com que houvesse pouco interesse na produção de materiais didáticos específicos para essa área de ensino. Como comenta Eres Fernández (2000: 60):

El poco interés por el estudio del español, marcadamente en las décadas de 60 y 70 y principios de los años 80, engendró una serie de dificultades que persistieron durante mucho tiempo. Entre ellas se pueden destacar: el reducido número de profesores que se licenciaron a lo largo de esos años, y los escasos materiales didácticos de enseñanza de español disponibles en el mercado brasileño.

(...)El reducido número de materiales didácticos disponibles, a su vez, se debe a la misma razón: si eran pocos los que deseaban aprender 


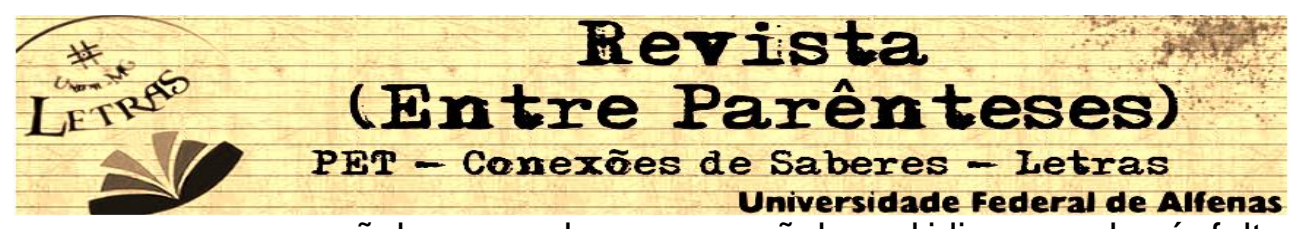

español y menos los que enseñaban el idioma, no hacía falta disponer de muchas publicaciones para ese fin. Así, frente a la poca demanda, nada o casi nada se produce para la enseñanza del español ya que el inglés predomina de forma prácticamente exclusiva.

Durante algumas décadas, como comenta Fernández, a produção de materiais didáticos para o ensino de língua espanhola esteve esquecida. Foi somente a partir dos anos 90 que o mercado e a produção de materiais didáticos para o ensino do espanhol começou a crescer no Brasil, principalmente graças aos acordos do MERCOSUL e a abertura de outros mercados comerciais, onde a língua espanhola ocupava lugar de destaque.

Com as novas possibilidades de trabalho e de ações comerciais que envolviam o espanhol, diferentes tipos de materiais e recursos didáticos, começaram a ser oferecidos a professores e alunos brasileiros. Atualmente temos à nossa disposição livros importados ou nacionais, materiais de áudio e vídeo ou plataformas de ensino ou com diferentes abordagens e adequados para as mais diversas idades ou situações de ensino.

A pluralidade de materiais oferecidos para o ensino do espanhol, porém, nem sempre significa que temos bons materiais ao nosso alcance. Como já dissemos, o professor deve selecionar o material que utilizará em suas aulas a partir de seus objetivos para aquele contexto de ensino, mas não podemos ignorar que muitos dos materiais que temos atualmente ignoram as nossas realidades de ensino e raros são os que apresentam o foco na questão da diversidade cultural dos povos hispânicos (com ou sem relação com a nossa cultura), conforme as diretrizes apresentadas pelas OCEM.

Temos de recordar que as OCEM são diretrizes para o ensino do espanhol em nosso país, e sendo um documento oficial, não se pode ignorá-las. Os apontamentos e diretrizes apresentadas pelo documento devem nortear a prática docente e consequentemente devem estar também refletidas no material que será utilizado para o ensino da língua espanhola. Entretanto, ainda que as Orientações esmiúcem temas como a escolha do material didático e sua aplicação no ambiente escolar, salientando que o professor deve optar pelos recursos mais adequados e por estratégias metodológicas plausíveis de acordo com os resultados almejados, o

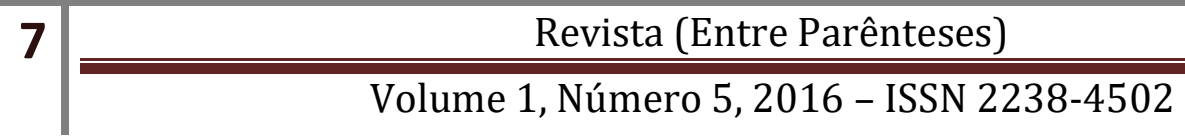




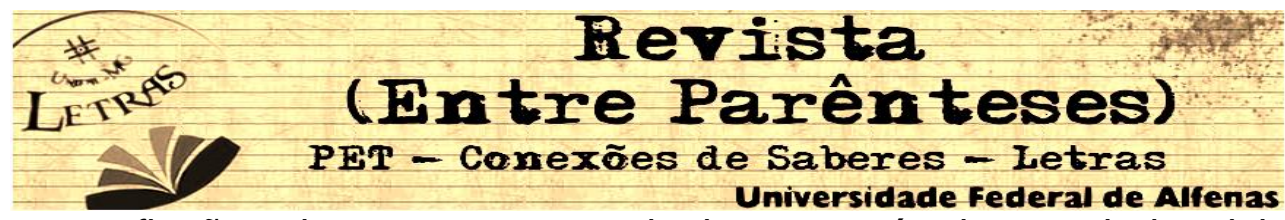

espaço para reflexão sobre as novas tecnologias e os métodos provindos delas quase nunca são levantados no documento.

O fato é que, com a presente era tecnológica, faz-se necessário pensar em outros exemplos de materiais didáticos, além do livro didático, que de fato estejam contextualizados à realidade atual dos alunos. Esses novos recursos digitais possibilitam novas formas de ensino/aprendizagem, pois possuem formatos diferentes dos utilizados convencionalmente no ambiente escolar.

Através dessa nova abordagem, acredita-se facilitar a real inserção do aluno no contexto linguístico e sociocultural da língua espanhola, uma vez que a facilidade de acesso às mídias contribui para a expansão dos instrumentos didáticopedagógicos adotados pelos docentes.

Assim, pensar no ensino, atrelando-o ao tecnológico, parece ser fundamental tanto para a aproximação à realidade vivida pelos discentes hoje, quanto para o próprio desenvolvimento do cenário escolar, que tem se mantido estático, por diversos motivos, que vão desde a falta de atualização ou formação adequada dos profissionais que nele atuam, à ausência de interação da comunidade escolar com ele. Além disso, para o ensino especifico da língua espanhola, os recursos tecnológicos contribuiriam demasiado, tanto pela aproximação linguística e geográfica existente entre os falantes do português e do espanhol quanto pela contextualização sociocultural e ideológica que coexiste em ambas as línguas.

O primeiro aspecto a se discutir é o significado do termo tecnologia. Compreendemos tecnologia como o "estudo de ferramentas, aparelhos, máquinas, dispositivos, materiais, objetivando uma ação deliberada e a análise de seus efeitos, envolvendo o uso de uma ou mais técnicas para atingir determinado resultado" (Kline, 1985 apudFRAGA, 2013, p. 9). Isto é, todos aqueles recursos que auxiliam na solução de problemas e que envolvem determinadas estratégias são materiais tecnológicos.

De difícil conceituação, as tecnologias da informação e da comunicação (TIC), que vem ganhando destaque desde os anos 90, são os recursos voltados especificamente para a propagação de informações. Elas se segmentam em várias seções, como expõe Pereira (2010): 


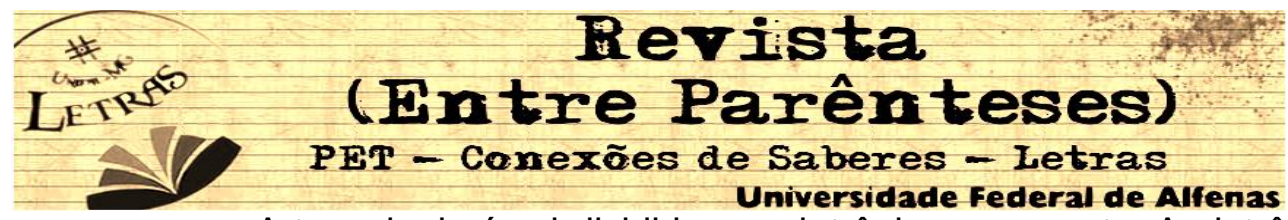

A tecnologia é subdividida em eletrônica e concreta. A eletrônica, por sua vez, está subdividida em digital e analógica. As digitais são: computadores, CD de áudio, CD-ROM, DVD etc. Já as analógicas são: rádio, televisão, telefone, cinema etc. A concreta está subdividida em material e corporal. A material são: livro; apostila; slides etc. Já a corporal são: palestras; dança; teatro; e canto. (p. 23)

Dessa forma, são muitos os exemplos de materiais tecnológicos, mas o intuito é abordar aqueles chamados de eletrônicos, que envolvem, principalmente, a internet em suas possíveis aplicações no ensino.

Santos et al ( $\mathrm{s} / \mathrm{d}, \mathrm{p} . \mathrm{3})$ afirmarão que os professores ainda se encontram despreparados para a efetiva utilização dos instrumentos tecnológicos em sala, seja no contexto da língua estrangeira ou em qualquer outra área. Essa deficiência pode se constituir em obstáculos, uma vez que, como já foi dito, todo o poder do material se encontra de posse do professor, e se este não for qualificado, sua efetividade não é garantida. Assim, é necessário que os docentes e as instituições de ensino promovam ações de integração aos materiais didáticos que envolvem a tecnologia, de maneira a se formarem tecnologicamente.

O ensino de espanhol como língua estrangeira ainda hoje se fixa demasiadamente na gramática e um dos principais benefícios oferecidos pelos materiais tecnológicos é a concreta utilização da linguagem. De fato, não se pode negar que o trabalho com os elementos linguísticos estruturais é de essencial importância na aula de língua estrangeira, mas existem diversos outros fatores tão importantes quanto, e que, infelizmente, não são considerados devidamente. Nascimento (2012) irá dissertar sobre o tema, e afirmará que

o trabalho com a língua estrangeira desenvolvido nas salas de aula ainda se concentra no estudo da gramática e tem no seu conjunto de regras um instrumento a ser seguido para expressar-se corretamente. Ensina-se a metalinguagem e não a língua; aprende-se a analisar as características estruturais e de uso de uma língua e não a dominar as habilidades necessárias para o uso em situações concretas de interação, que requerem a produção e o entendimento de enunciados. (p. 444)

É pensando nesta deficiência existente nas aulas de língua, que acreditamos serem os materiais tecnológicos, elementos benéficos para a construção do 


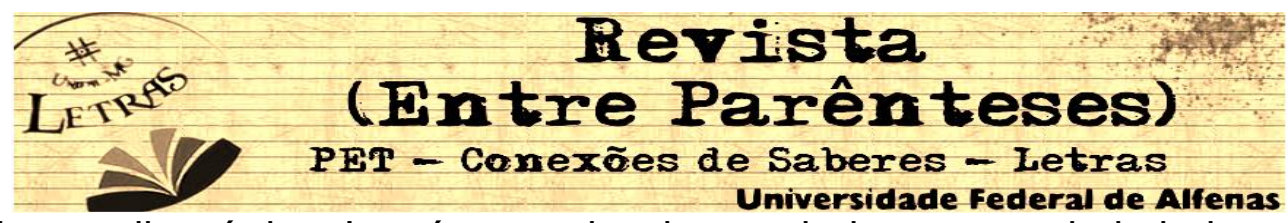

conhecimento linguístico. Isto é, se a abordagem dada ao espanhol ainda se atém a contextos fictícios e que não proporcionam o desenvolvimento de competências essenciais à interação objetiva, a utilização da tecnologia pode possibilitar uma real inserção do aluno a essas situações verídicas proporcionadas pela língua.

Por exemplo, com a internet é possível acessar inúmeros sites de relacionamento e comunidades virtuais cuja interface permite o convívio com milhares de pessoas de diferentes países. Esse convívio englobaria o desenvolvimento de habilidades que são essenciais para a comunicação, tais como a adequação de estruturas a seu real funcionamento e a interação com componentes socioculturais e pragmáticos, que ficam à margem nas práticas didático-pedagógicas conduzidas somente pelo livro didático.

Sobre isso, ainda retomando a Nascimento (2012), argumentamos que a linguagem é um fenômeno de muitas dimensões, e que, portanto, o "conhecimento do falante é um fenômeno multifacetado" (p. 8), que não deve se limitar a apenas um aspecto, e os recursos tecnológicos contribuem diretamente neste sentido.

O falante dispõe de um conhecimento linguístico que engloba tanto as estruturas da língua quanto o seu funcionamento em diversas situações, isto é, no seu discurso estão envolvidas questões como a seleção de conteúdo, variedade linguística, organização global do texto, estruturas morfossintáticas e vocabulário. (ibidem)

Por sua vez, Silva (s/d) irá afirmar que a internet funciona como um meio de motivação no que se refere à contextualização de determinadas atividades. Assim, se a tarefa pede a utilização de certas estruturas ou de um gênero específico, como a carta, é possível que, de fato, o aluno entre em contato com o mundo linguístico, travando relações com um falante da língua e compartilhando suas produções em contextos reais. O professor passa a ser, assim, o mediador entre essas relações e não "o único destinatário" (p. 265). Além disso, por tais relações se darem em língua espanhola, o nível de dificuldade de compreensão diminui e a motivação para estudar este idioma aumenta exponencialmente.

A internet ainda possibilita espaços de conversação, como chats ou grupos de discussão, nos quais é possível desenvolver as habilidades auditivas e de pronuncia. Esses espaços são fundamentais para a aprendizagem do espanhol, uma 


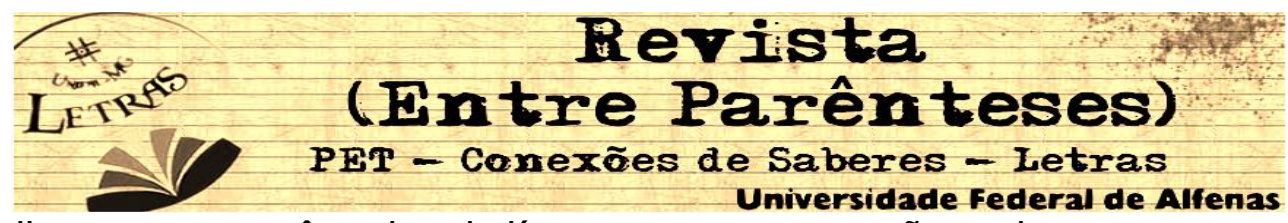

vez que ilustram certos ângulos da língua que somente são realmente compreendidos quando demonstrados na prática. Por exemplo, a questão das diversas variedades faladas da língua espanhola, que existem no mundo todo, e podem, muito bem, serem trabalhadas tomando-se reais amostras linguísticas. A experiência verídica seria muito mais enriquecedora neste caso, em contraste com um possível empreendimento, por parte do professor, de "imitar" as demais variantes.

Além disso, temos ainda outras possibilidades de recursos tecnológicos que poderiam ser utilizados no contexto de ensino e aprendizagem de espanhol, como, por exemplo, os inúmeros sites. Com uma diversidade gigantesca, os sites abordam todos os temas possíveis, nos mais diversos acentos da língua espanhola e proporcionam o contato dos alunos com textos autênticos. Os sites ainda proporcionam a mirada sobre a cultura do outro e tudo o que isso implica.

Temos ainda os blogs, os jogos interativos que permitem a aproximação ao espanhol através de diálogos ou missões que devem ser realizadas em grupo, os aparelhos portáteis de som e projetores de filmes, (mais conhecidos do cotidiano de ensino) além do crescente número de e-books e audiobooks, dentre muitos outros recursos materiais que podem ser aproveitados para a promoção do processo de ensino-aprendizagem.

Um dos recursos mais presentes na época atual, e que o ambiente escolar ainda não aprendeu a integrar ao ensino são os celulares de última geração, que contém diferentes opções tecnológicas, se transformado em um dos materiais mais acessíveis e adaptáveis à realidade escolar.

A seleção das múltiplas possibilidades oferecidas pelo mundo tecnológico em que nos encontramos é, talvez, a tarefa mais complicada no momento de adoção a essas práticas. É preciso refletir conscientemente sobre as dificuldades da situação do ensino na qual o docente se encontra e sobre a adequação de tais materiais às necessidades dos alunos, além de estabelecer metodologias apropriadas na aplicação dos mesmos. O professor, como já salientamos, também deve conter em sua formação todo o trabalho com a tecnologia.

Em resumo, os elementos tecnológicos complementariam o ensino regular do espanhol como língua estrangeira, pois suas possibilidades são incontáveis e trazem aspectos que dificilmente seriam abordados se não fosse por sua presença. 


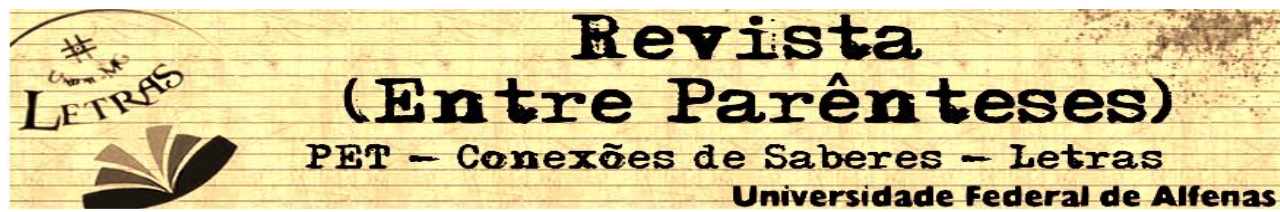

Finalizamos com uma reflexão de Leal (s/d) sobre o uso das TICs no ambiente de ensino-aprendizagem de uma língua estrangeira (ou segunda língua):

Pensar o uso das TICs como instrumento facilitador da inserção do aprendiz de uma segunda língua (L2) como sujeito modificador e construtor de discursos sobre o mundo, sobre o outro, sobre si próprio e sua realidade pode transformar o ensino de E/LE não somente em exercício de socialização de saberes, mas, também, de fortalecimento das relações interpessoais, de estreitamento dos vínculos de pertencimento e de participação social nas discussões sobre questões concernentes ao universo cultural da língua-alvo. (grifo do autor, p. 3)

O uso das tecnologias como materiais/recursos didáticos se mostra como um meio de aproximar o processo de ensino-aprendizagem de situações de uso da língua autênticos, já que esses recursos, muitas vezes, são capazes de promover não só o contato com a língua estrangeira, mas também a interação com falantes e com conhecimentos com os quais não teria acesso sem o uso deles.

Assim, pode-se dizer que inserção de materiais tecnológicos no ensino é positiva, também e talvez, principalmente, pela capacidade humanizadora provinda deles. Isto é, por detrás de todo o mundo das tecnologias, está a primazia pela socialização de ideias e saberes, que promovem vínculos, edificam identidades e constroem cidadãos melhores e mais bem formados no que diz respeito às compreensão e convivência com a diferença.

\section{Referências bibliográficas}

BOHN, H. I. Avaliação de materiais. In: Tópicos de linguística aplicada. Florianópolis: UFSC, 1988. p. 292-311.

BRASIL. Orientações Curriculares Nacionais para o Ensino Médio. Ministério da Educação. Secretaria de Educação Média e Tecnológica. Brasília, 2006.

FERNÁNDEZ, I. G. M. E. La producción de materiales didácticos de español lengua extranjera en Brasil. In: Anuario brasileño de estudios hispánicos. Suplemento. El hispanismo en Brasil. Consejería de Educación y Ciencia en Brasil. Brasilia: Embajada de España en Brasil. 2000. p. 59-80.

FRAGA, Luíze Bueno Ferreira Fonseca de. O uso das tecnologias digitais da informação e comunicação no ensino de língua estrangeira. Porto Alegre, 2013. Disponível 


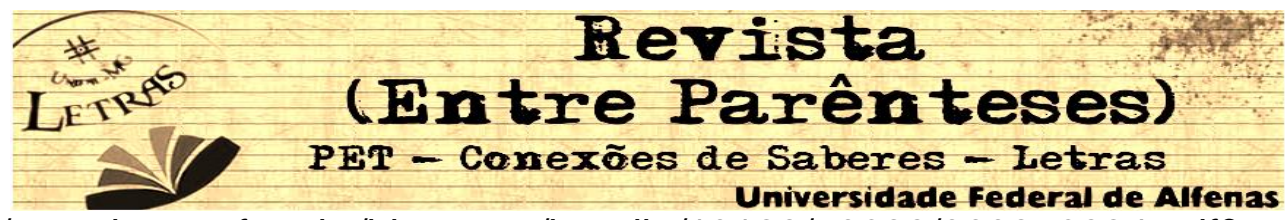

$<$ https://www.lume.ufrgs.br/bitstream/handle/10183/70689/000876984.pdf?sequence $\equiv 1>$. Acesso em novembro de 2014.

GARGALLO, I. S. Lingüística aplicada a la enseñanza-aprendizaje del español como lengua extranjera. Madrid: Arco Libros. 1999.

GOETTENAUER, E. Espanhol: língua de encontros. In: SEDYCIAS, J. (Org.). 0 ensino do espanhol no Brasil: passado, presente, futuro. São Paulo: Parábola Editorial, 2005.p. 61-70.

LEAL, Juliana Helena Gomes. O ensino de E/LE e as novas tecnologias: repensando o trabalho com as atividades de compreensão auditiva. $\mathrm{S} / \mathrm{d}$. Disponível em <http://nehte.com.br/hipertexto2009/anais/m-o/o-ensino-de-ELE.pdf>. Acesso em novembro de 2014.

NASCIMENTO, Mizael Inácio do. Espanhol no Ensino Médio: como o ensino dessa língua pode vir a ser mais proveitoso? Disponível em $<$ http://www.revistaeutomia.com.br/v2/wp-content/uploads/2013/01/Espanhol-noEnsino-M\%C3\%A9dio como-o-ensino-dessa-1\%C3\%ADngua-pode-vir-a-ser-maisproveitoso.pdf>. Acesso em novembro de 2014.

PEREIRA, Elani Marinho. O USO DAS MíDIAS NO ENSINO DE LÍNGUA ESPANHOLA: Uma visão dos alunos do curso de Letras Espanhol. João Pessoa, 2010. $<$ http://www.cchla.ufpb.br/ccl/images/Documentos/TCCs/2010\%20elani\%20marinho $\% 20$ pereira\%20-

$\% 200 \% 20$ uso $\% 20$ das $\% 20$ mdias $\% 20$ no\%20ensino\%20de\%20lngua $\% 20$ espanhola $\%$ 20uma\%20viso\%20dos\%20alunos\%20do\%20curso\%20de\%20letras\%20espanhol.p df $>$. Acesso em novembro de 2014.

SANTOS, Tássia Ferreira; BEATO, Zelina; ARAGÃO, Rodrigo. AS TICS E O ENSINO DE LÍNGUAS. s/d. Disponível em <http://www.uesc.br/eventos/sepexle/anais/10.pdf>. Acesso em novembro de 2014.

SILVA, Beatriz Pereira da. A INTERNET NO ENSINO DE ESPANHOL PARA ALUNOS BRASILEIROS. S/d. Disponível em $<$ http://www.filologia.org.br/xiv cnlf/tomo 1/258-290.pdf >. Acesso em novembro de 2014. 